\title{
Natureza e Participação Social, uma Nova Estética para o Desenho Urbano
}

\author{
Maria Angela Faggin Pereira Leite
}

\begin{abstract}
As formas da paisagem são o resultado do equilibrio entre múltiplas forças e processos temporais e espaciais. Em certa medida, a paisagem é um reflexo da visão social do sistema produtivo e transforma-se sempre que as teorias, princípios filosóficos ou necessidades que as criaram não são mais reais ou evidentes.

Parece, assim, natural que o Paisagismo passe por transformações, tanto em relação ao seu referencial teórico, quanto em relação à sua atuação no campo do projeto. Entre essas transformações, a questão da modificação dos critérios de intervenção e dos padrões estéticos do projeto é discutida neste artigo.
\end{abstract} \begin{abstract}
The shape of the landscape is the result of the balance between several temporal and spacial forces and processes. In a way, landscape is reflex of the social view of the productive system and changes whenever theories, philosophic principles or the needs for its existence are not real or evident anymore.
\end{abstract}

So, its seems natural that Landscape Architecture goes naturally through transformations or changes both in relation to its theoretical framework and its praxis. Among these changes the question related to a new way of projectual praxis and aesthetic criteria asks for a deeper discussion.
Artigo elaborado com base na Tese de Doulorado "Natureza e panticipação social, uma nova estética para o desenho urbano". apresentada em outubro de 1992.

Orientador: Prof. Dr. Millon Santos 


\section{Introdução}

A paisagem, reflexo da relação circunstancial entre o homem e a natureza, resulta da ordenação do entorno a partir de uma imagem idealizada. Simultaneamente reflexo da estrutura da sociedade e objeto de intervenção, a paisagem é projetada e construída a partir de elaborações filosóficas e culturais que resultam, tanto da observação objetiva do ambiente, quanto da experiência individual ou coletiva em relação a ele.

Como reflexo da estrutura da sociedade, a paisagem mostra uma permanente procura de formas que expressem graus de integração e compatibilidade entre as manifestaçōes políticas, econômicas, técnicas, científicas e artísticas dessa sociedade. A observaçāo atenta dessas manifestaçōes sociais nos permite captar a realidade em transformação e exprimi-la em obras específicas, que são os projetos paisagísticos.

Como objeto de intervençāo desses projetos, a paisagem revela o processo dinâmico de expressão do imaginário social e de seus padrões estéticos e culturais, cuja origem dificilmente pode situar-se em um único campo específico de conhecimento.

$\mathrm{Na}$ antigüidade, os jardins eram obras da reflexão dos filósofos, poetas, monges e pintores, fechados para o mundo exterior e intimamente relacionados com a contemplação e a meditação.

$\mathrm{Na}$ atualidade são obras de arquitetura e devem procurar, também nos processos econômicos, políticos e históricos da sociedade, os fatos que explicam e justificam sua forma e seu caráter.

A fusāo entre esses dois modos de expressāo da realidade exige o estabelecimento de uma relação mais concreta entre a compreensão filosófica do espaço e do tempo absolutos - a reflexão sobre a paisagem - e a apreensão empírica do espaço e do tempo limitados - o projeto de Paisagismo. O longo processo de transição entre a visão rural da paisagem como natureza contemplativa e a compreensão de seu potencial de expressão de conflitos e desigualdades sociais geradas pelo processo de urbanizaçāo, envolveu o abandono de crenças e dogmas e sua progressiva substituição por propostas e projetos que melhor atendessem às questōes originadas pela transformação da sociedade, ampliando, tanto o referencial teórico, quanto a atuaçāo formal do Paisagismo.

\section{A Industrialização, a Urbanização e o Mundo da Produção de Massa}

O Paisagismo entrou no séc. XX marcado por um legado teórico de espírito essencialmente agrário. Essa abordagem adaptou-se muito mal às novas paisagens de subúrbio da cidade industrial e revelou-se absolutamente inadequada para responder às questōes então emergentes, como a pobreza, a fome, as desigualdades e o excesso de populaçāo.

A associação, nos projetos paisagísticos, entre os aspectos naturais e construídos de cada lugar e a conseqüente concepção da paisagem como uma seqüência fluente de articulações entre funçōes urbanas e rurais, foi o primeiro passo em direção à visão do espaço público como ponto de convergência entre cidade e campo, convergência que tem um significado econômico historicamente datado. De fato, o violento processo de industrializaçāo/urbanizaçāo das cidades européias no séc. XIX e das cidades americanas no início do séc. $X X$, exigiu a mudança das condições de reprodução de uma classe trabalhado-

(1) Considera-se aqui entre as condiçoes de reproduçăo da classe trabalhadora, năo apenas o direito à moradia, à alimentaçăo e à saúde, mas também ao lazer em seus inúmeros aspectos. ra numerosa, desumanizada e despersonalizada, porque culturalmente ligada às práticas e tradições rurais ${ }^{1} \mathrm{O}$ surgimento dos grandes parques urbanos foi uma resposta a essa exigência. 
As posteriores mudanças nas relações internacionais, o colapso e a transformação dos antigos imperialismos, o reajustamento das relaçōes entre os povos, marcaram um momento de tendências confusas e incertas, cujo aspecto mais significativo foi seu caráter mundial, conseqüência da industrialização, da vida urbana, da produção de massa, das novas formas de comunicação e transporte.

A arquitetura funcional moderna tinha um projeto estético e político de combate à frivolidade superficial $\Theta$ ao ecletismo do final do séc. XIX. A beleza que resultava da função, dentro de uma estética severa, a idéia de que da fusão da arte com a indústria resultaria o progresso social ou de que bastava produzir um novo espaço urbano para que surgisse uma nova ordem social, aliada ao carisma dos grandes arquitetos modernistas, levou a arquitetura moderna a uma codificação, a uma gramática uniforme, que passou a ser praticada em todos os lugares do mundo.

A afirmaçāo do edifício como monumento e como obra auto-referencial estava inserida numa forma de produção da cidade que prescindia de reflexōes sobre especificidades locais: a ruptura com a tradição exigia que a modernidade fosse buscar em si mesma suas coordenadas e suas normas, fazendo farto uso da razão para explicar a rejeição às instâncias transcendentes.

A destruição da organização social em todos os seus aspectos - inclusive a destruição do tecido urbano - também correspondia ao espírito da modernidade, porque sua proposta racional se adequava melhor a um espaço totalmente construído ou reconstruído de acordo com o rigor da boa forma. Dividir o espaço, romper os limites existentes, estabelecer fronteiras, criar unidades, tudo era parte do processo de reconstrução de um mundo previamente despojado de suas garantias institucionais ${ }^{2}$

Todas essas questões passaram a preocupar os envolvidos nas discussões do urbanismo e a exigir outra forma de atuação do Paisagismo, cujas intervenções limitadas a jardins e parques públicos iam progressivamente perdendo significado.

A partir da década de 30, especialmente nos Estados Unidos, o adensamento das cidades e a generalização do uso do automóvel como meio de transporte provocou mudanças mais intensas na relação entre espaços livres e edificados, tornando necessária a busca de alternativas de projeto que enfrentassem essas questōes. À medida que o aumento da população, da velocidade dos meios de transporte e da eficiência das comunicaçōes tornavam a vida mais complexa, emergia também a consciência de que o Paisagismo podia responder aos interesses dos diversos grupos sociais através de projetos de caráter mais urbano e que os valores, os hábitos e os objetivos dos usuários podiam sugerir os critérios desses projetos.

Ao final da II Guerra Mundial, o declínio do colonialismo, sua substituição por novas relações de dependência e a ampliação dos mercados e relaçōes econômicas internacionais, tornou global o processo de urbanização já acentuado nos países de capitalismo consolidado, levando o Paisagismo, tanto na prática de projeto, como no campo teórico, a procurar alternativas para as questōes originadas por essa nova ordem mundial.

Embora esboçando os primeiros passos em direção a intervençōes essencialmente urbanas, o Paisagismo manteve ainda por longo tempo uma atuação especificamente ligada à discussão de aspectos estéticos, sem questionar a qualidade da paisagem produzida pela interação entre as forças estruturais impostas pelos planos de desenvolvimento propostos em escala mundial e a rotina das práticas locais dos cidadāos submetidos a essas determinaçōes.
(2) Uma discussáo mais ampla dessa quesıáo consta do cap 5. da tese "Novos valores des truiçáo ou desconstrução" 
Na década de 50, Garret Eckbo revolucionou o pensamento paisagístico ao afirmar que os projetos de intervenção na paisagem destinam-se resolver contradiçōes entre a natureza e a sociedade, que suas linhas emergem do exame atento das manifestaçōes técnicas, econômicas e culturais da sociedade juntamente com a observação das condiçōes específicas de organização de cada lugar e que esses dois conjuntos de conhecimento jamais podem ser utilizados separadamente ${ }^{3}$

O Paisagismo ingressou então num períado de participação na vida urbana com o surgimento de numerosas frentes de avanço que buscavam a identificação e a humanização da paisagem do mundo da produção de massa.

\section{Do Visual ao Ambiental}

Nesse contexto, as revoluções científicas, sociais, políticas e de comunicações da década de 60 - a conquista da Lua, os movimentos estudantis e pacifistas, as lutas políticas no Leste europeu, o desenvolvimento das telecomunicações - contribuíram para ampliar os referenciais que apoiavam as propostas de intervenção na paisagem. A passagem do projeto de pequeno porte para 0 projeto de sistemas de espaços livres urbanos e regionais começou a tomar forma como decorrência de questões relevantes para a estruturação do território em suas diversas escalas e a compreensão dos processos que determinavam essa estruturaçāo tornou os projetos mais socializados e, simultaneamente, mais integrados com as questōes naturais de cada lugar.

Por outro lado, o florescimento das teorias sociais de reivindicação e participação popular encontrou nos espaços públicos urbanos o veículo ideal para sua manifestação. Os projetos de Paisagismo procuravam atender às necessidades sociais de concentração e manifestação pública, organizando espaços de caráter cívico e os reflexos estéticos dessas inovaçōes puderam ser observados principalmente na alteraçāo das relaçōes dimensionais, na introduçāo de elementos lúdicos e nas propostas que contemplavam a participaçāo dos usuários na configuração final do projeto: praças e parques nāo eram mais construídos para a contemplação, mas para uma saudável, enriquecedora e efetiva utilização coletiva.

A imagem e a interpretação da paisagem começam a ser utilizadas como forma de introduzir a questāo da contextualizaçāo do projeto, posteriormente ampliada pela incorporação de conhecimentos relativos à administração, utilização e conservaçāo dos recursos naturais. Como reflexo imediato das acaloradas discussões ecológicas de 68 e 72, o Paisagismo ampliou as dimensōes de sua atuação, defendendo que a elaboraçāo local de um projeto contextualizado dependia da compreensão dos processos econômicos, sociais e naturais em escala mundial, nacional e regional. Ian McHarg, pioneiro na proposição metodológica e na elaboração de projetos que obedeciam a essa linha de pensamento, destacou a necessidade de compatibilizar processos naturais e sociais com a finalidade de solucionar os conflitos que o modelo de desenvolvimento econômico delineava para a década de 70 .

A crise do Estado autoritário, com a extinção de algumas das mais fortes e prolongadas ditaduras mundiais - Portugal, Espanha, Grécia, Nicarágua -

(3) As idéias e propostas de Eckbo tiveram forte influência no desenvolvimento da chamada Escola Paulista de Paisagismo no Brasil, onde chegaram trazidas por Roberto Coelho Cardozo, pioneiro na implantaçáo da disciplina de Paisagismo na FAUUSP associada ao fim do colonialismo, que pode considerar-se extinto do mundo a partir de 1979, e à revolução das comunicaçōes, teve um papel importante na redefinição do público e do privado, alterando padrōes culturais e artísticos vigentes e envolvendo a construção de paisagens mais identificadas com as questōes do quotidiano das comunidades. A pressão demográfica, por sua 
vez, pedia soluçōes habitacionais urbanas homogêneas e de dimensões reduzidas, com amplos espaços livres coletivos, facilmente identificáveis na produção do Paisagismo da década de 70.

A face cosmopolita das novas relações mundiais incorporou ao projeto paisagístico tanto o caráter simbólico/representativo - pela utilização de elementos com significado cultural local - quanto o caráter de arte em escala monumental - presente, por exemplo nas intervençōes e instalaçōes do escultor Christo - justificado pela possibilidade de apreender grandes porções do território através de vôos, fotografias aéreas e imagens de satélites. Mas levou também à adoção de um partido de projeto lógico neutro e apolítico que procurava distanciar-se dos conflitos e interesses contraditórios entre grupos sociais, surgidos a partir da década de 60 , e sem nenhuma perspectiva concreta de solução.

O caráter profundamente recessivo e neoconservador da política dos anos 80 , agravou ainda mais esse quadro pela ampliação do leque de questōes sociais originadas na esfera econômica - prosperidade da economia européia, desafio, pelo Japão, do parque industrial americano, falência do modelo intervencionista estatal, surgimento dos tigres asiáticos - na esfera política - guerras sangrentas e invasões localizadas, atentados terroristas, queda de praticamente todos os regimes políticos fechados, extinção da URSS - e na esfera da saúde pública - fome, pela incapacidade de distribuição de alimentos, epidemias, disseminação da aids.

Os estudiosos das teorias de urbanizaçāo foram levados a formular propostas tão variadas e desvinculadas entre si quanto essas questōes que, naquele momento, exigiam respostas urgentes porém inexistentes.

A censura, a pregação da moralidade, a corrida armamentista, provocaram uma onda de ataques às teorias sociais democráticas de participação e reivindicaçāo popular, dando lugar a um liberalismo que não conseguia ocultar a impossibilidade de convivência entre grupos sociais tão diferentes em seus interesses e formas de manifestação. Dilemas e conflitos mundiais de caráter ecológico - desenvolvimento versus conservação de recursos naturais catástrofes atômicas - Chernobyl, Three Miles Island, Goiânia - problemas urbanos incontroláveis - aumento da violência e do desemprego, surgimento e ascensāo de seitas de caráter racista e discriminatório - indicaram a retomada de padrōes clássicos de projeto de espaços públicos segregacionistas e intimidatórios, como forma de tentar manter sob controle situações originárias da estrutura de um mundo politicamente conflitante e economicamente injusto. "As cidades e as regiōes não cresciam mais como uma miríade de tensões público-privadas, mas como mutações deliberadas, engendradas por um Estado burocrático e uma sociedade civil corporativa, ambas as esferas guiadas pelo retorno financeiro. ${ }^{4}$

Se a paisagem revelava, de forma evidente, os temores e preconceitos resultantes desses conflitos sociais, do ponto de vista estético, os projetos de Paisagismo configuravam-se com verdadeiras exibições do poder e da riqueza acumulados pelos países e lugares centro desses acontecimentos. O Brasil não escapou a essa influência e, se por um lado, a falência do Estado não permitiu o patrocínio de espaços públicos de caráter segregacionista, o projeto paisagistico dos espaços privados - condomínios fechados, áreas de lazer dirigido, shopping centers - foi tão violentamente marcado por essas arbitrariedades como em qualquer outro lugar do mundo. A simetria rigorosa e a organização ortodoxa dos projetos aliada à fragmentação característica do período, resultou em intervençōes nāo mais integradas ao contexto, mas, na

(4) DEAR, Michael 1988, p 26 
maioria das vezes, em visivel choque com ele, deixando a desagradável impressão de um cenário sem nenhuma relação com as reais atividades que se desenvolviam nas cidades, numa profusão de cores e formas sem significado social relevante.

A coesāo, tão fortemente defendida pela modernidade, esfacelou-se diante de nossos olhares atônitos $e$ as totalidades homogêneas que embasaram as práticas do moderno deram lugar a uma dispersão plural onde cada coisa procurava seu próprio sentido, exigindo a criação de referenciais próprios.

A desmitificação da razāo, a rejeição da unidade, a falta de credibilidade em relação aos grandes discursos de emancipação e às explicações racionais que correlacionavam os âmbitos teórico, prático, político, ético e os articulavam e justificavam global e unitariamente foram responsáveis pelo surgimento de novas formas de estruturação do quotidiano.

A mundialização da informação e da comunicação tornou a velocidade das mudanças sociais, econômicas e políticas muito intensa, impedindo o controle das variáveis que incidem sobre a estruturação e a configuração da paisagem. A organização dos espaços passa a ser feita pelo estabelecimento de relações qualitativas entre seus componentes e as formas arquitetônicas precisam, necessariamente, identificar-se com o contexto.

Esse processo multidimensional de qualificaçāo e identificação envolve o estabelecimento de relações com o conjunto de elementos físicos, naturais e culturais que caracterizam esse contexto e confere à paisagem uma dimensão ambiental, uma visão crítica, que decorre da integração perceptiva - integração entre todos os sentidos - e que é inerente à própria dimensāo ambiental. É da própria qualidade dessa dimensão, onde se entrelaçam signos pertencentes a diversos meios de comunicação - sonoro, olfativo, visual, térmico, informacional - a transformação contínua das estruturas da paisagem no tempo e no espaço, acompanhando a velocidade vertiginosa de transformação do contexto.

O Paisagismo é forçado a deslocar-se do campo visual - onde tinha o papel de organizar espaços - para o campo ambiental - onde tem o papel de qualificar espaços - alterando radicalmente a reflexão sobre a paisagem e, conseqüentemente, os padrões estéticos do projeto.

\section{A Nova Estética}

Esses padrões estéticos emergem sempre de questōes determinadas pelos princípios econômicos, políticos, científicos, filosóficos e artísticos que refletem o momento e necessitam de um referencial que os sustente, aglutine e explique, conferindo-lhes uma validade capaz de diferenciá-los dos modismos e das soluções meramente formais.

Se é verdade que as modificações culturais e comportamentais podem induzir uma saudável renovação da metodologia e das práticas de projeto, é igualmente verdadeiro que essas modificações podem provocar perdas, sob certos aspectos, na interação entre a obra e o usuário. O desmoronamento de princípios, dogmas e crenças exige a construção de novos paradigmas, tarefa nem sempre simples e imediata. O estranhamento, a obra difícil, manifestações da reflexão e da procura desses paradigmas, correm sempre o risco de nāo serem compreendidos, de provocarem desinteresse ou, o que é pior. rejeição. 
Diferentemente da modernidade, que efetuava sua reflexão a partir dos princípios filosóficos que a explicavam e não a partir do confronto com a realidade ou com a materialidade do quotidiano, o momento atual utiliza esse confronto, ou melhor, toma esse confronto como ponto de partida para elaborar sua reflexão. As normas inflexíveis da modernidade convidavam à crítica e à ridicularizaçāo como caminho para a reação e a mudança. Na atualidade, a ausência de normas rigorosas resulta no pastiche, na imitação, na cópia, no fake reciclado como proposta de mudança. Essa atitude crítica é, porém, altamente intelectualizada, seletiva e elitista porque o humor e a sátira que the sāo inerentes se perdem ou se transformam em simples associaçōes formais quando suas referências não podem ser entendidas.

A prática de uma gestão territorial democrática, que parece delinear-se no período atual, genericamente rotulado de pós-moderno, supõe a constituição de um novo corpus, de novas referências, reconhecidas por todos os cidadãos e não apenas por um pequeno grupo de iniciados. Nesse sentido, a Arquitetura e o Urbanismo reclamam uma nova concepção de arte, uma abertura do sistema de referências e de escolha de materiais e técnicas, a aceitação da existência de atividades humanas pluralistas e contraditórias, conduzidas também pela imaginação e não somente pela razão ${ }^{5}$

A inclusão de espaços livres públicos nas várias concepçōes urbanas ao longo da história comprova a crença de que o contato com a natureza é simbólico e significativo na vida das pessoas e que a cidade não é uma entidade independente dos processos naturais ${ }^{6}$

Mudanças profundas no modo de vida e nas necessidades sociais nos levam a reconsiderar a forma e o conteúdo desses espaços como parte de um ambiente urbano em evolução, visando protegê-lo e assegurar sua continuidade. A explosão demográfica, a natureza pluralística da sociedade, o amplo espectro de interesses e conflitos emergentes entre classes sociais e as diversas necessidades de cada comunidade são considerações importantes na reflexão sobre a paisagem e vão manifestar-se, no âmbito do projeto de Paisagismo através de novos valores e critérios.

A citação é uma forma de seleção e utilização de elementos extraídos de fatos culturalmente significativos ou marcantes. A ação de qualificar os espaços decorre da possibilidade de relacionar imagens que nos são oferecidas pela observação direta do mundo real e imagens abstratas e interiorizadas que nos são transmitidas pela cultura.

A consciência de que o projeto não tem a capacidade de alterar a realidade trouxe consigo a liberdade de trabalhar com o simbólico, com a riqueza de significados, mesmo que nem sempre claros, conectando fatos pertencentes a diferentes planos de percepção, ampliando as possibilidades de interpretaçāo, de compreensão do ritmo, da história, das contradiçōes, das discriminações, permitindo ver a realidade e alterá-la, não por meio do projeto, mas pela modificação das relaçōes sociais.

A outra face do simbólico é a referência do lugar, fundamental para impedir a destruição completa das raizes e valores coletivos. A atual aceleração das mudanças apaga rapidamente a história, instalando uma espécie de processo de amnésia coletiva. O sentido do lugar, a expressão dos processos naturais originais anteriores à urbanização podem ser revividos em segmentos simbólicos do projeto, que nos relembrem onde estamos. Identificar características e processos naturais e criar formas urbanas relacionadas com eles pode resultar em espaços livres públicos estreitamente associados com cursos de água, planícies de inundação, terrenos frágeis, espaços que ressaltem a interdependência entre processos urbanos e naturais.

(5) GLUSBERG. Jorge 1987, p 81

(6) LAURIE. Michael 1989,p 48 
A integração com o entorno, possivel apenas quando existe a disposição prévia de entender como uma determinada porção da paisagem foi construída, tem a importância fundamental de revelar aspectos da razāo da intervenção. É inerente a esse processo a escolha de um referencial, um elemento que, naquele contexto, aglutine, explique e confira validade ao projeto. Esse referencial, que não é meramente formal, mas estrutural, porque sua seleção decorre da leitura do lugar, pode ser identificado pela observação atenta da forma de participação do usuário e da comunidade. Espaços públicos urbanos rejeitados ou abandonados, freqüentemente resultam da incapacidade de seu projeto de estimular o interesse do usuário, manter sua atençāo, permitir interaçōes sociais e adaptar-se a mudanças contínuas. O projeto nāo deve jamais impor, mas apenas sugerir comportamentos. "E o intérprete que, no próprio momento em que se abandona ao jogo das livres relaçōes sugeridas, volta continuamente ao objeto para nele encontrar as razōes da sugestão, a mestria da provocaçāo, a esta altura não desfruta mais unicamente de sua própria aventura pessoal, mas desfruta a qualidade própria da obra, sua qualidade estética." 7

Espaços livres públicos, projetados para atender a um único propósito, não sāo apenas enfadonhos e desagradáveis, são também incapazes de auto-enriquecimento, uma vez que excluem de sua utilizaçāo uma parte da sociedade.

Espaços públicos flexíveis e menos rigorosamente definidos, adaptáveis a atividades e propósitos sociais que possam vir a surgir futuramente, podem ser as soluçōes mais sensiveis nas atuais condiçōes de diversidade social e cultural.

A concretização, sob forma de objetos paisagísticos, dos valores e critérios de um novo periodo histórico, ocorre por meio da utilização de técnicas construtivas e materiais que pertencem ainda ao periodo anterior. Assim, as formas arquitetônicas decorrentes da adoçāo de novos paradigmas são obtidas a partir de adaptaçōes dos materiais existentes, aí incluidas, no caso específico do momento atual, adaptaçōes à velocidade de mudança das necessidades sociais. Talvez seja essa dificuldade que leve os trabalhos de vanguarda a adotar, na qualificaçāo dos espaços públicos, soluçōes provisórias, objetos removiveis, painéis e reformas de fachada, numa tentativa de testar possibilidades de resposta às peculiaridades do período. É possível que, a partir do momento em que os novos paradigmas encontrem os materiais adequados à sua expressão, a estética que atualmente se insinua na fronteira entre a realidade e a imaginação revele sua verdadeira face.

\section{Bibliografia}

CALVINO, Italo. Lezione Americane: sei proposte per il prossimo milenio. Milano: Garzanti, 1988.

DEAR, Michael. State, territory and reproduction: planning in a post-modern era. In: Tecnologia e gestáo do território. Rio de Janeiro: UFRJ, 1988.

ECKBO, Garret. Landscape for living. New York: F W. Dodge Corp, 1950.

ECO, Umberto. Obra aberta. Sāo Paulo: Perspectiva, 1991.

GLUSBERG, Jorge. Los signos de la ciudad y una poetica del entorno. Revista de Estética, Buenos Aires, n. 5/6, p. 79-85, 1987

LYOTARD, Jean-François. O pós-moderno. Rio de Janeiro: José Olympio, 1988.

MCHARG, Ian. Design with nature. New York: The Natural History Press, 1969.

RAVERA, Rosa Maria. Estetica y semiotica. Rosario: Fundacion Ross, 1988. 